\title{
Inhibition of type I interferon signaling abrogates early Mycobacterium bovis infection
}

Jie Wang ${ }^{1,2}$, Tariq Hussain ${ }^{1}$, Kai Zhang ${ }^{3}$, Yi Liao', Jiao Yao ${ }^{1}$, Yinjuan Song ${ }^{1}$, Naveed Sabir ${ }^{1}$, Guangyu Cheng ${ }^{1}$, Haodi Dong ${ }^{1}$, Miaoxuan $\mathrm{Li}^{1}$, Jiamin $\mathrm{Ni}^{1}$, Mazhar Hussain Mangi ${ }^{1}$, Deming Zhao ${ }^{1}$ and Xiangmei Zhou ${ }^{1 *}$

\begin{abstract}
Background: Mycobacterium bovis (M. bovis) is the principal causative agent of bovine tuberculosis; however, it may also cause serious infection in human being. Type I IFN is a key factor in reducing viral multiplication and modulating host immune response against viral infection. However, the regulatory pathways of Type I IFN signaling during M. bovis infection are not yet fully explored. Here, we investigate the role of Type I IFN signaling in the pathogenesis of M. bovis infection in mice.

Methods: C57BL/6 mice were treated with IFNAR1-blocking antibody or Isotype control $24 \mathrm{~h}$ before M. bovis infection. After 21 and 84 days of infection, mice were sacrificed and the role of Type I IFN signaling in the pathogenesis of $M$. bovis was investigated. ELISA and qRT-PCR were performed to detect the expression of Type I IFNs and related genes. Lung lesions induced by M. bovis were assessed by histopathological examination. Viable bacterial count was determined by CFU assay.

Results: We observed an abundant expression of Type I IFNs in the serum and lung tissues of M. bovis infected mice. In vivo blockade of Type I IFN signaling reduced the recruitment of neutrophils to the lung tissue, mediated the activation of macrophages leading to an increased pro-inflammatory profile and regulated the inflammatory cytokine production. However, no impact was observed on T cell activation and recruitment in the early acute phase of infection. Additionally, blocking of type I IFN signaling reduced bacterial burden in the infected mice as compared to untreated infected mice.

Conclusions: Altogether, our results reveal that Type I IFN mediates a balance between M. bovis-mediated inflammatory reaction and host defense mechanism. Thus, modulating Type I IFN signaling could be exploited as a therapeutic strategy against a large repertoire of inflammatory disorders including tuberculosis.
\end{abstract}

Keywords: Immunity, Mycobacterium bovis, Type I interferon signaling, Inflammatory response, Macrophages polarization, Neutrophils

\section{Background}

Tuberculosis is one of the major public health problems and it is caused by Mycobacterium tuberculosis (M. tuberculosis). According to WHO survey, about 1.3 million deaths and 10 million new cases (out of 1.3 million deaths, 0.3 million were HIV-positive) were reported in 2017 (World Health Organization, 2018) [1]. Mycobacterium

\footnotetext{
* Correspondence: zhouxm@cau.edu.cn

'Key Laboratory of Animal Epidemiology and Zoonosis, Ministry of Agriculture, National Animal Transmissible Spongiform Encephalopathy Laboratory, College of Veterinary Medicine, China Agricultural University, Beijing, China

Full list of author information is available at the end of the article
}

bovis (M. bovis), a member of Mycobacterium tuberculosis complex $(M T C)$, is the central causative agent of bovine tuberculosis; however, it also infects a wide range of hosts including human beings. Clinically, human tuberculosis caused by M. tuberculosis or M. bovis is undistinguishable [2].. It has been reported that number of mechanisms are involved in the development of host-immune response against mycobacterial infections [3-6], however, further understanding of the host-pathogen interaction and the intracellular survival of $M$. bovis is necessary for controlling the infection.

(c) The Author(s). 2019 Open Access This article is distributed under the terms of the Creative Commons Attribution 4.0 International License (http://creativecommons.org/licenses/by/4.0/), which permits unrestricted use, distribution, and reproduction in any medium, provided you give appropriate credit to the original author(s) and the source, provide a link to the Creative Commons license, and indicate if changes were made. The Creative Commons Public Domain Dedication waiver (http://creativecommons.org/publicdomain/zero/1.0/) applies to the data made available in this article, unless otherwise stated. 
The family of Type I IFN comprises of a dozen IFN- $\alpha$ subtypes, IFN- $\beta$, as well as IFN- $\varepsilon$, IFN- - , and IFN- $\delta$ which are secreted upon attachment of infectious agents to the pattern-recognition receptors (PPRs) of host cells [7]. All Type I IFN similarly bind to a heterodimeric receptor such as IFNAR1 and IFNAR2; however, the signaling of subtypes of Type I IFN via these receptors results in different functions. In addition, it has been determined that the activity of IFNs depends upon the specificity for the attachment and the potential to induce changes in the receptors $[7,8]$. Increasing evidences suggest that IFN- $\beta$ has a high binding capability to the specified receptors of IFNs for signal generation and the induction of downstream gene expression [9].

Early studies have investigated that Type I IFN contribute to the progression of clinical tuberculosis [10-13]. However, further study is prerequisite to investigate the pathway of Type I IFN signaling that could modulate the host-pathogen interaction during tuberculosis. Therefore, we hypothesized that Type I IFNs may be a modulator of the host immune response against $M$. bovis infection. We found that the expression of Type I IFN and interferon stimulated genes (ISGs) was upregulated in mouse during $M$. bovis infection. Previous studies have demonstrated that high pathogenic strains of $M$. tuberculosis induced an increase production of Type I IFN and subsequently inhibit the expression of pro-inflammatory cytokines leading to abrogation of Th1 responses [14-17]. Reports also suggest that Type I IFN contributes in the recruitment of various myeloid cells which result in the severity of inflammation-dependent lung injury and also promote the dissemination of infection $[18,19]$. In addition, drugs that limit Type I IFN induction have been developed to improve the efficacy of tuberculosis treatment [20]. In the current study, we hypothesized that signaling of Type I IFN is crucial in host immune response against $M$. bovis infection. We observed that blockade of Type I IFN signaling reduces the recruitment of inflammatory myeloid cells to the lung tissue, which inhibit the activation of macrophages and result in a pro-inflammatory phenotype thus promoting anti-mycobacterial Th1 response in the early acute phase of infection. Altogether, our findings suggest that therapeutic agents that limit Type I IFN induction could be a better strategy for the control of $M$. bovis infection.

\section{Methods}

\section{Preparation of cell culture}

In the current study, we used murine macrophages (BMDMs and J774a.1 cells). Bone marrow derived macrophages (BMDMs) were obtained from femur and tibia of C57BL/6 mice as described previously [21]. In brief, cells were obtained from femur and tibia of 6 to 8 weeks old mice and cultured in RPMI1640 (Hyclone) medium supplemented with $10 \%$ FBS in the presence of $10 \mathrm{ng} /$ $\mathrm{ml} \mathrm{M-CSF}$ (Pepro Tech) and 1\% streptomycin and penicillin (Gibco) in $\mathrm{CO}_{2}$ incubator at $37^{\circ} \mathrm{C}$ for 7 days. Fresh cell culture medium was added at day 4 of incubation and removed the dead or non-adherent cells. At day 8, the adherent BMDM cells were collected and transferred to 12-well cell culture plates for further experiments. J774a.1 cells were collected from cold storage $-80{ }^{\circ} \mathrm{C}$ (previously obtained from the Cell Culture Center, Xiehe Medical University (Beijing, China)) and cultured for 2 to 3 days in cell culture flasks in DMEM (Hyclone, Logan, UT, USA) medium in the presence of $10-15 \%$ FBS (Gibco, Grand Island, NY, USA), and 1\% streptomycin and penicillin (Gibco) at $37^{\circ} \mathrm{C}$ in $\mathrm{CO}^{2}$ (5\%) incubator [22]. After 2 to 3 days, J774a.1 cells were transferred into 12-well culture plates for further experiments.

\section{Preparation of bacterial culture}

In our current experiment, we used virulent strain of $M$. bovis. M. bovis Beijing strain C68004 was obtained from China Institute of Veterinary Drug Control (CVCC, China). A stock culture of $M$. bovis was maintained in Middlebrook 7H9 medium (Difco) enriched with 10\% albumin-dextrose-catalase (ADC), $2 \mathrm{mg} / \mathrm{L}$ sodium pyruvate and $0.05 \%$ Tween- 80 at $37{ }^{\circ} \mathrm{C}$ under biosafety conditions level 3 (BSL3). M. bovis was cultured for 2-3 weeks at $37^{\circ} \mathrm{C}$ to a concentration of $10^{7-8} / \mathrm{ml}$ before used for cells or animal infection.

\section{Mice model of $M$. bovis infection}

C57BL/6 female mice (6-8 weeks of age) were obtained from Vital River Laboratories (Beijing, China). All mice were maintained in a strict biosafety measures in BSL-III laboratory of China Agricultural University, under the protocols of the Laboratory Animal Ethical Committee of China Agricultural University (Protocol 20,110,61101 ). Mice were housed in groups as many as 5 mice per cage with free access to feed and water under sterilized condition. Mice were infected with $M$. bovis at $100 \mathrm{CFU}$ (Colony-forming units) via intranasal (i.n) route. The suspension of $M$. bovis bacilli was prepared in sterilized PBS, the negative controlled animals were treated to PBS. Mice were properly anaesthetized by injecting PBS diluted Zoletil 50 (50 mg/kg; Virbac, France) via intraperitoneal route [23] before infection with $M$. bovis. One day post infection (p.i), about five mice were selected randomly and sacrificed by cervical dislocation, under ethics requirements [24], as to calculate viable bacilli in the lung tissues. Next, 6 mice were randomly selected from each experimental group at 21 and 84 day post infection. Blood samples were collected from orbital route [25] of mice after proper anaesthetizing by intraperitoneal injection of PBS diluted Zoletil 50 (50 mg/kg; Virbac, France). Serum samples were obtained from blood 
by low-speed centrifugation and tissues (lung, spleen) were collected aseptically from all experimental animals and stored at $-80^{\circ} \mathrm{C}$ till further experiments.

\section{In vivo IFNAR1 blocking antibody treatments}

In each group, 12 mice C57BL/6 mice were treated twice with $500 \mu \mathrm{g}$ of anti-IFNAR1 antibody (clone MAR1-5A3; Biolegend San Diego, CA, USA) or mouse IgG1 $(500 \mu \mathrm{g})$ isotype control (clone MOPC21; Bio X Cell) one day prior to $M$. bovis infection and at 6 weeks post infection through intraperitoneal (i.p) injection. For the enumeration of total viable bacilli, lung and spleen tissues were lysed with small ceramic beads in phosphate buffered saline (PBS), in a tissue homogenizer apparatus (WKT technology) in accordance with the guidelines of manufacturer. An appropriate tenfold serial dilution was prepared in PBS. The dilutions were separately plated in triplicates on Middlebrook 7H11 agar supplemented with ampicillin $(10 \mu \mathrm{g} / \mathrm{ml})$ and sodium pyrovate $(2-4 \mathrm{mg} /$ liter). After $2-3$ weeks of incubation at $37^{\circ} \mathrm{C}, \mathrm{M}$. bovis colonies were counted [21].

\section{IFNAR1 blocking antibody treatment in vitro}

To investigate the inhibitory effect of Type I interferon signaling in vitro, BMDMs were treated with $1 \mu \mathrm{g} / \mathrm{ml}$ of IFNAR1 blocking antibody (Biolegend) for $2 \mathrm{~h}$. Then the cells were washed three times with warm PBS and infected with $M$. bovis at multiplicity of infection (MOI) 10 and incubated at $37^{\circ} \mathrm{C}$ for $24 \mathrm{~h}$.

\section{IFN- $\beta$ production assay}

The level of IFN- $\beta$ in the serum samples was determined by using ELISA assay as previously described (Cusabio, Wuhan, Hubei, China) according to the manufacturer's protocols [21]. Briefly, $100 \mu \mathrm{l}$ of standards and samples were added in respective wells of 96 wells antibody coated plate. After incubation and washing steps, conjugated secondary antibodies were added for $1 \mathrm{~h}$ followed by same washing steps. Then substrate solution was added in each well followed by addition of stop solution. A standard curve was obtained by using 2-fold dilutions of the standard for each independent experiment. The concentration of cytokines was calculated using a standard curve.

\section{Multiplex cytokine assays}

The lung tissues were homogenized in PBS $0.05 \% \mathrm{v} / \mathrm{v}$ Tween 20 with a supplementation of protease inhibitor cocktail (Roche). The detection of multiple cytokines was carried out by using multiplex bead-based immunoassay kits (Millipore) according to the manufacturer's protocol. MAGPIX ${ }^{\odot}$ instrument (Luminex, USA) was used to perform multiplex bead-based immunoassay for the detection of multiple cytokines.

\section{Quantitative RT-PCR assay}

The cDNA synthesis from total RNA (50 ng) was performed by using the Revert Aid first-strand cDNA synthesis Kit (Thermo Fisher Scientific, MA, USA) according to the manufacturer's protocol. For the quantitative analysis of mRNA, real time-PCR (qRT-PCR) was performed by using AceQ qPCR SYBR Green Master Mix kit (Vazyme Biotech, Nanjing, China) according to the manufacturer's instructions. $\beta$-actin was used as a house keeping gene for data analysis. The sequences of primers used in the current study are mentioned in Table 1. Amplifications were performed with the 700 Fast Real-Time PCR Systems (ViiA7 Real-time PCR, ABI). Thermal cycling conditions were $95^{\circ} \mathrm{C}$ for $5 \mathrm{~min}$ then 40 cycles at $95^{\circ} \mathrm{C}$ for $10 \mathrm{~s}$ and $60^{\circ} \mathrm{C}$ for $30 \mathrm{~s}$. All fold changes were analyzed by using the $\Delta \Delta \mathrm{Ct}$ method [22]. Samples were measured in triplicate from three independent experiments.

\section{Histopathology}

For histopathology analysis, the left lung lobe was selected from mice of all experimental groups. 10\% formalin buffer was used as a tissue fixative solution and then the lung tissues were sectioned at $5 \mu \mathrm{m}$ of thickness, followed by H\&E or Ziehl-Neelsen staining methods. The inflammatory changes in the lung tissue was measured by observing the $H \& E$ stained lung sections under light microscopy at low $(\times 10)$ and high $(\times 40)$ magnifications. The superior lobes of the left lung were stained with H\&E to assess the severity of inflammation; minimum 10 microscopic fields were selected for each section. The level of inflammation in the lung sections was quantified by measuring the area of lesion out of the total area of the section by using ImageJ software (National Institutes of Health, USA).

\section{Immunohistochemistry}

The lung tissues that were already fixed in formalin buffer (10\%) were paraffinized and sectioned for immunohistochemical analysis. Briefly, after deparaffinization and antigen retrieval, the lung sections were blocked with BSA for $15 \mathrm{~min}$ at $37^{\circ} \mathrm{C}$ [26]. After blocking, the sections were incubated at $4{ }^{\circ} \mathrm{C}$ with anti-mouse IFNAR1 (Biolegend) or anti-mouse IFN- $\beta$ (Santa Cruz Biotechnology, CA, USA) overnight followed by HRP-labeled secondary rabbit antimouse IgG antibodies (Proteintech, Wuhan, China). The enzymatic activity was revealed by using 3,3 '-Diaminobenzidine (DAB). Digital images were collected on Olympus microscope fitted with DS-Ri2 camera. To quantify the intensity of IFNAR1 and IFN- $\beta, 3$ lung sections from independent animals of each group were visualized under low and high power of magnifications. The stained area compared with the total tissue area was determined by using Image-J software. 
Table 1 Primers used for Quantitative Real-Time PCR

\begin{tabular}{|c|c|c|}
\hline Gene name & Forward primer (5'-3') & Reverse primer $\left(5^{\prime}-3^{\prime}\right)$ \\
\hline Ifnbl & AAGAGTTACACTGCCTTTGCCAT & CACTGTCTGCTGGTGGAGTTCATC \\
\hline Ifnar1 & СTCCATCTCCTGCTTAGTGT & ATTAGTTACTGTGGGTACTTGTG \\
\hline Irf7 & ACTTCAGCACTTTCTTCCGAGAAC & AGGTAGATGGTGTAGTGTGGTGAC \\
\hline Oas2 & AAAGTCCTGAAGACCGTCAAGGG & ACAACAATGTCAGCATCTGATCCC \\
\hline $\operatorname{lgs} 15$ & AGCAATGGCCTGGGACCTAAAG & AGTCACGGACACCAGGAAATCG \\
\hline Ifng & AGCAACAACATAAGCGTCAT & CCTCAAACTTGGCAATACTC \\
\hline Tnf & CAAAATTCGAGTGACAAGCCTGT & CCACTTGGTGGTTTGCTACGA \\
\hline Nos2 & TCCTCACGCTTGGGTCTTGTTC & TCCAACGTTCTCCGTTCTCTTGC \\
\hline Mrcl & AATGCCAAAAATTATTGATCGTG & ACGGTGACCACTCCTGCTG \\
\hline Yml & TACCCTATGCCTATCAGGGTAAT & CCTTGAGCCACTGAGCCTTC \\
\hline $\operatorname{Arg} 1$ & AATGAAGAGCTGGCCTGGTGTGGT & ATGCTTCCAACTGCCAGACTGTG \\
\hline T-bet & CCCCTGTCCAGTCAGTAACTT & CTTCTCTGTTGGCTGGCT \\
\hline Gata-3 & AAGAAAGGCATGAAGGACGC & GTGTGCCCATTTGGACATCA \\
\hline Foxp3 & СTTCACCAAGGTGAGCGAGT & СTTCTGTCTGGAGTGGCTGG \\
\hline$\beta$-actin & ССTTCTGACCCATTCCCACC & GCTTCTITGCAGCTCCTTCG \\
\hline
\end{tabular}

\section{Lung cell isolation}

Right lung lobes were washed with PBS before excision, and minced on the ice. The minced lung tissues were incubated with DMEM containing $50 \mu \mathrm{l}$ Collagenase 1 (1 mg/ m1) (Solarbio, Beijing, China) and $50 \mu \mathrm{l}$ DNase 1 (150 U/ $\mathrm{m} 1$ ) (Roche Biochemicals) for $1 \mathrm{~h}$ at $37^{\circ} \mathrm{C}$ and shacked once every $15 \mathrm{~min}$. After that tissue homogenates were passed through a cell strainer of $70 \mu \mathrm{m}$ pore size (BD Falcon, NY, USA) to make single cell suspension. Lung cells were centrifuged in complete DMEM for $5 \mathrm{~min}$ at 1000 rpm for obtaining leukocytes from cell suspension. After centrifugation, the supernatants were removed and the cell pellets were resuspended, and erythrocytes were lysed with Red Blood Cell Lysis Buffer (MultiSciences, Hangzhou, China) by keeping at room temperature for $5 \mathrm{~min}$. About $10 \mathrm{ml}$ of DMEM containing 10\% FBS was added to stop the lysis reaction, and after centrifugation the supernatant was removed. After that the cells were resuspended in PBS and the number of cells was counted [26].

\section{Flow cytometry}

For differential quantification of innate immune cells, isolated leukocytes for both lung and spleen tissue were stained with antibodies against Ly6G PerCP-Cyanine5.5 (eBioscience, California, USA), CD11b-APC, CD11cFITC, Ly6C-PE, CD11c-PE, MHC-II-FITC, CD40-FITC, CD80-FITC, CD86-FITC CD4-FITC and CD8-APC (all from eBioscience). For leukocytes analysis, single-cell suspensions from lungs were stimulated with $10 \mu \mathrm{g} / \mathrm{ml}$ of EAST- 6 in the absence or presence of $4 \mu \mathrm{g} / \mathrm{ml}$ brefeldin A (Sigma, St. Louis, USA) for $6 \mathrm{~h}$ at $37^{\circ} \mathrm{C}$ [26]. CD206-PE (eBioscience) antibody was used for the detection of intracellular markers of lymphocyte subsets.

\section{Statistical analysis}

The data was analyzed by using GraphPad Prism 5 software USA. Student t test was applied for comparing between two groups. One way or two way ANOVA was applied for the comparison of multiple groups.

\section{Results}

The induction of type I interferon during $M$. bovis infection

In order to identify Type I interferon signaling that is critical for the pathogenesis of M. bovis, we infected C57BL/6 mice with virulent $M$. bovis by intranasal route (i.n). After 21 and 84days of infection, mice were sacrificed, and lungs, spleen and serum samples were collected aseptically for analysis of IFN- $\beta$ and IFNAR1. We observed a significant increased level of mRNA expression of Ifnb1 and Ifnar1 in the lung (Fig. 1a and b) and spleen tissue (Additional file 1: Figure S1A and S1B) at both 21 and 84 days after infection in comparison with uninfected PBS control mice. Similarly, the protein level of IFN- $\beta$ and IFNAR1 was also significantly high in the lungs and spleen tissue of $M$. bovis infected mice than PBS controls at both 21 and 84 days post-infection (Fig. 1c and d, Additional file 1: Figure S1C and D). In addition, we found an increased level of IFN- $\beta$ in the serum of $M$. bovis infected mice than PBS control mice (Fig. 1e), as well as IFN-responsive genes such as Irf7, Oas2 and Isg15 at the indicated time points (Fig. 1f and g, Additional file 1: Figure S1E and S1F).

Next, we infected J774A.1 and BMDM cells with $M$. bovis to determine the expression of Ifnb1. The quantitative real time PCR results revealed a significant increase in the expression of Ifnb1 at 6,12 , and $24 \mathrm{~h}$ post- 
A

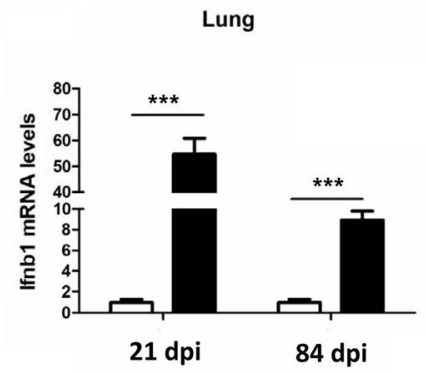

C

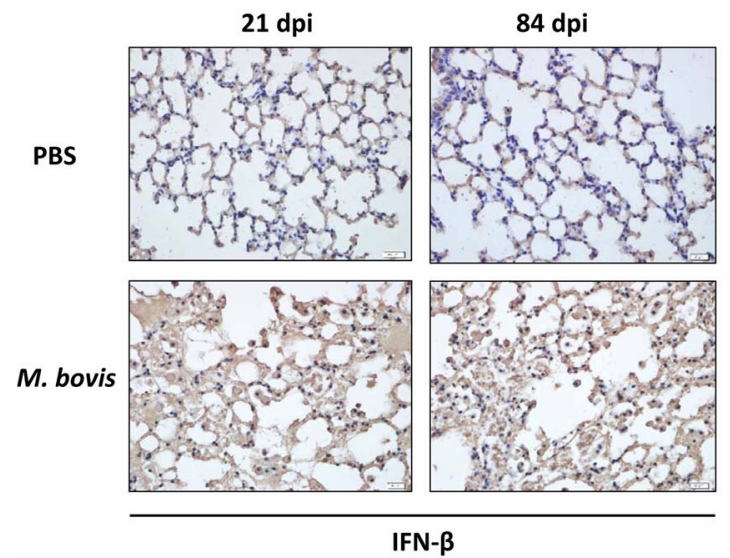

E

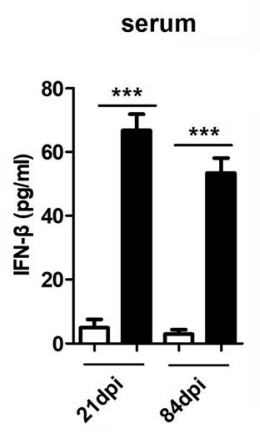

H

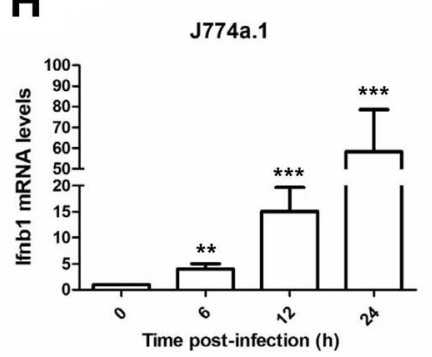

B
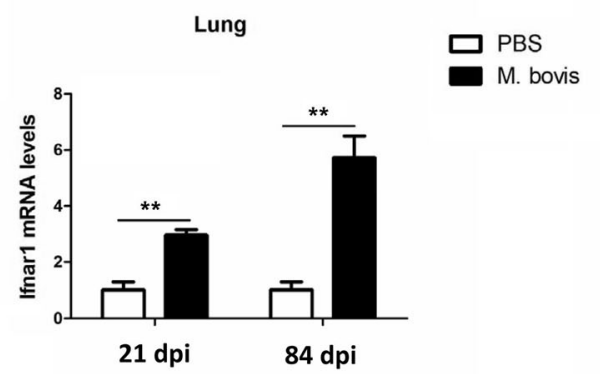

D

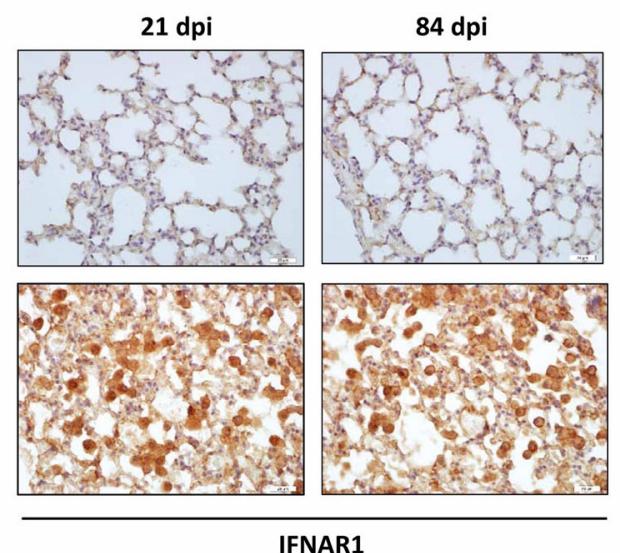

G

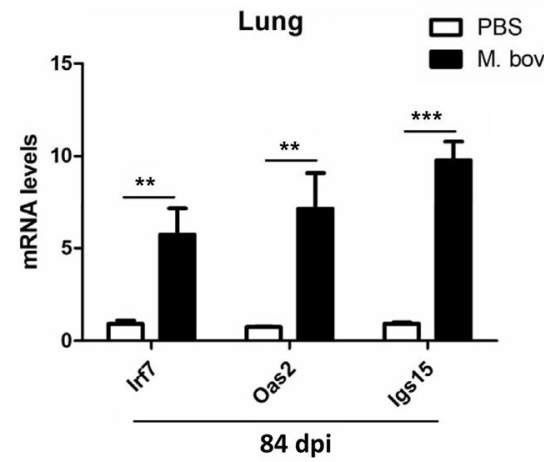

Fig. 1 (See legend on next page.) 
(See figure on previous page.)

Fig. 1 M. bovis induces type I interferon in C57BL/6 mice. (b-e)Wild type female C57BL/6 mice were challenged with M. bovis (100 CFU) or PBS by intranasal (i.n) route. Mice $(n=3)$ from each group were analyzed for gene and protein expression at 21 and 84 days post-infection. (a) Ifnb1 and (b) Ifnar1 mRNA expression in the lung tissues were checked by qRT-PCR. Gene expression values were normalized to the housekeeping gene $\beta$-actin. (c) IFN- $\beta$ and (d) IFNAR1 expression in the lungs were detected by IHC method; scale bars, $20 \mu m$. Original magnification, 100x. (e) The level of IFN- $\beta$ in the blood serum was determined by ELISA. mRNA isolated from lung tissues was probed for the expression of indicated genes by qRT-PCR at (f) $21 \mathrm{dpi}$ and (g) 84 dpi. (h) J774A.1 and (i) BMDM cells were infected with M. bovis at a multiplicity of infection (MOI) of 10 for the indicated time, mRNA was isolated and probed for the expression of Ifnb1 gene by qRT-PCR. Data were normalized to housekeeping gene $\beta$-actin. Data was obtained from three independent experiments for in vitro study. Data is presented as mean $\pm \mathrm{SD}\left({ }^{*} P<0.05\right.$; ** $P<0.01$; $* * * 0<0.001)$

infection (Fig. 1h and i). Together, these results suggest that $M$. bovis induces the production of Type I IFN during infection.

\section{Type I IFN signaling contributes to the pathogenesis of $M$. bovis}

We further investigated the role of Type I IFN in the pathogenesis of $M$. bovis, and found that IFNAR1 blockade diminished IFN-responsive Irf7, Oas2 and Isg15 genes expression in the lung and spleen tissues (Additional file 2: Figure S2A and S2B), indicating its ability to inhibit Type I IFN signaling. IFNAR1 blockade also decreased IFN- $\beta$ production in blood serum of $M$. bovis infected mice (Additional file 2: Figure S2C). Next, we examined the susceptibility of C57BL/6 mice to pulmonary infection by $M$. bovis after treatment with IFNAR1-blocking antibody ( $\alpha$ IFNAR1 mice) or mouse IgG1 isotype control antibody (Isotype mice). Initially, we evaluated the survival rate of $\alpha$ IFNAR1 and Isotype mice after intraperitoneal infection with a low dose (100 CFUs) of $M$. bovis. We found that $\alpha$ IFNAR1 treated mice were less sensitive to infection, with a significant decrease in mortality rate and increased survival time after infection. In addition, $\alpha$ IFNAR1 mice survived acute (day 21 post-infection) and chronic infection (day 84 post-infection), while Isotype treated mice rapidly lost their body weight and half of the mice were died within 40 days post-infection (Fig. 2a and b). Next, we measured total viable $M$. bovis bacilli in the lung and spleen of infected mice at various time points post infection. We found significantly reduced viable bacilli in the lung and spleen tissues of $\alpha$ IFNAR1 treated mice as compared to Isotype treated group at both 21 and 84 days post infection (Fig. 2c and d). Similarly, reduced number of Acid-fast $M$. bovis bacilli were observed in lung sections of $\alpha$ IFNAR1 treated mice as compared with Isotype treated mice (Fig. 2e). Histological examinations of lungs sections revealed that granulomatous inflammatory lesions were significantly sever in the Isotype treated mice than $\alpha$ IFNAR 1 mice (Fig. 2f and g). Collectively, these findings demonstrate that Type I IFN signaling induced by $M$. bovis significantly promotes bacterial proliferation and contributes towards the pathogenesis of $M$. bovis infection in mice.

\section{Type I IFN signaling mediates lung inflammatory} cytokines that correlate with disease progression

Next, we evaluated the effect of Type I IFN signaling on the regulation of various cytokines. We quantified the levels of multiple cytokines in lung tissue samples by using multiplex bead-based immunoassay kits. We found significantly high levels of IFN $-\gamma$ and IL- $1 \beta$ in $\alpha$ IFNAR1 treated mice while low levels were observed in Isotype mice at 21 days post-infection (Fig. 3a, b). In contrast, the level of IL-10 and IL- 6 in $\alpha$ IFNAR1 treated mice was decreased as compared to Isotype mice at day 21 postinfection (Fig. 3c, d). Interestingly, we also found no significant difference in the production of IL-12, TNF- $\alpha$, IL-17 and IL-4 at day 21 post infection between $\alpha$ IFNAR1and Isotype treated mice. (Fig. 3e-h). Similarly, at day 84 post-infection, no clear difference was observed in the concentration of IFN- $\gamma$, IL- $1 \beta$, TNF- $\alpha$, IL-12, IL6, IL-10 and IL-4 in the both groups of mice (Fig. 3a-h). These results indicate that Type I IFN signaling contributes towards inflammatory reactions during early $M$. bovis infection.

\section{Type I IFN signaling regulates the accumulation and activation of myeloid cells in the lung during $M$. bovis infection}

Our approach, based on Type I IFN receptor blocking antibodies, allowed us to examine how Type I IFN signaling affects lung myeloid cell populations during $M$. bovis infection. As shown by flow cytometry (Fig. 4), we observed reduced lung pathology associated with reduction in the recruitment of neutrophils into the lung tissue of $\alpha$ IFNAR1 mice, though no significant difference was found in the population of alveolar macrophages, myeloid DCs, recruited macrophages and monocytes between $\alpha$ IFNAR1 and Isotype mice (Fig. 4a-f). Consistent with flow cytometry assay, histological assay revealed a noticeable reduction in the population of neutrophils in the lung sections of $\alpha$ IFNAR1 mice at day 21 post-infection (Fig. $4 \mathrm{~g}$ and h). These findings suggest that Type I IFN produced locally in lungs plays a significantly role in the migration of neutrophils to the lungs in the early phase of $M$. bovis infection. The blockade of $\alpha$ IFNAR1 rescue mice from adverse inflammatory reactions by preventing the excessive migration of neutrophils to the lung tissue. 


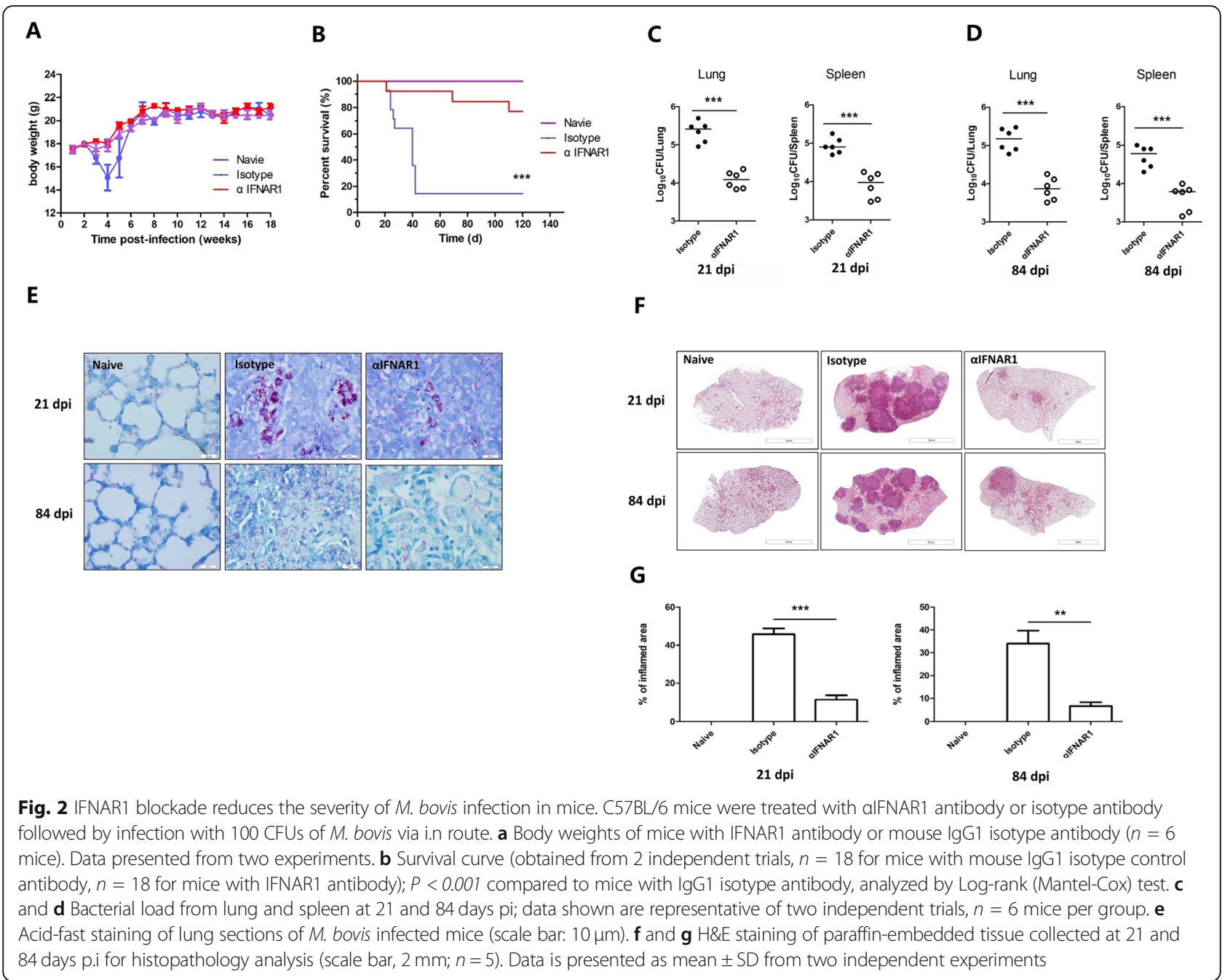

Next, we sought to determine the expression of MHC class II and co-stimulatory molecules on myeloid cells. We observed that $\alpha$ IFNAR1 mice showed a significantly high level of MHC class II expression on myeloid DCs compared with Isotype mice at 21 days post-infection (Fig. 4i). On contrary, IFNAR1 blockade had no noticeable effect on the expression levels of CD40, CD80 and CD86 (Fig. 4j-l). Our observations reveal that IFNAR1 blockade decreased the number of recruited neutrophils and lead to a weaker activation of myeloid DCs in the lungs during early $M$. bovis infection.

Type I IFN signaling mediates macrophage polarization toward an anti-inflammatory profile during $M$. bovis infection

In the next experiment, we assessed whether the signaling mechanism of Type I IFN could affect macrophage polarization during $M$. bovis infection. BMDMs treated with $\alpha$ IFNAR1 antibody exhibited no difference in the expression of the M1 markers such as Nos2 (nitric oxide synthase 2) and $\operatorname{Tnf}$ as compared to control group at 24 $\mathrm{h}$ post-infection (Fig. 5A). In contrast, these macrophages displayed a decreased expression of the M2 markers such as Arg1, Ym1, and Mrc1 (mannose receptor C-type 1) at $24 \mathrm{~h}$ post-infection (Fig. $5 \mathrm{~b}$ ). These findings show that Type I IFN induced by $M$. bovis-activated macrophages can directly shift the profile of macrophages into anti-inflammatory phenotype.

The increased level of Type I IFN leads to the attenuation of macrophage phenotypes in the lungs of $M$. bovisinfected mice. Early study reported that increased production of Type I IFN is associated with clinical tuberculosis [10], therefore, we determined the effect of blocking of Type I IFN signaling in the $M$. bovis-infected mice. Gene analysis in the lung tissues of $\alpha$ IFNAR1 mice showed a decreased in the expression of the M2 markers such as Arg1, Ym1, and Mrc1 (Fig. 5c-e), while high expression level of M1 markers such as Nos2 and Ifng were found compared with Isotype mice at 21 days post-infection (Fig. $5 \mathrm{f}-\mathrm{h}$ ) but no difference was observed at 84 days post infection. 


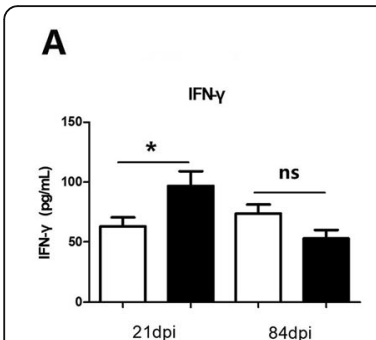

E

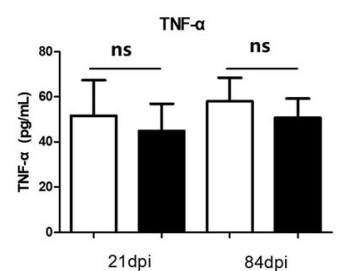

B

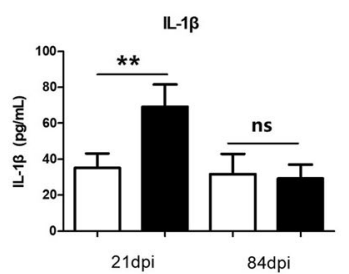

F

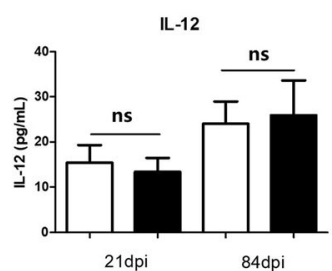

C

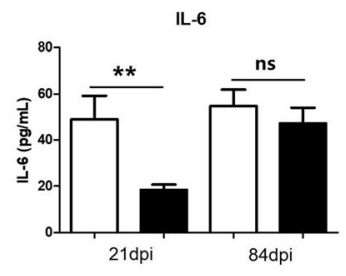

G

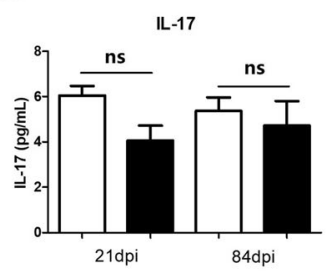

D

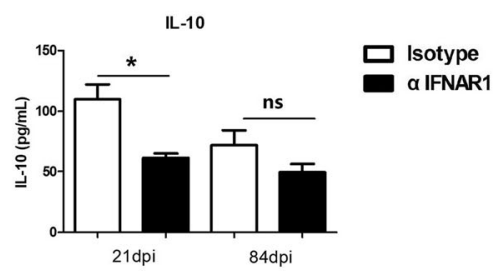

H

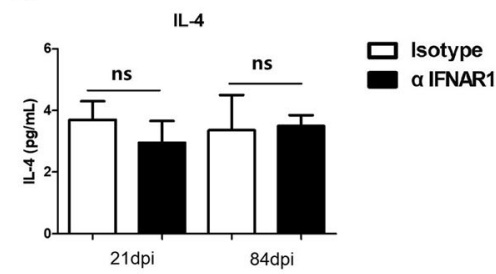

Fig. 3 The effect of IFNAR1 blockade on cytokine production in M. bvois infected mice. (A-H) lung homogenates from mice treated with alFNAR1 or isotype antibody followed by $M$. bovis infection was analyzed for cytokines production at 21 and 84 days p.i $(n=6)$; (a) IFN- $\gamma$, (b) IL-1 $\beta$, (c) IL-6, (d) IL-10, (e) TNF-a, (f) IL-12, (g) IL-17, (h) IL-4. Data shown is presented as mean \pm SD from two independent experiments. ${ }^{*} P<0.05$; $\left.* * \quad P<0.01\right)$

In addition, flow cytometric analysis of the $\mathrm{CD}_{11} 1 \mathrm{~b}^{+}$ $\mathrm{F} 4 / 80^{+}$macrophage population in the lung tissue of $\alpha \mathrm{IF}-$ NAR1 mice revealed an increased population of $\mathrm{CD}^{+} 6^{+}$ (M1) (Fig. 5i, j), while substantially reduced population of $\mathrm{CD}^{206}{ }^{+}$(M2) macrophages (Fig. 5k, l). These observations are in line with our initial hypothesis that loss of Type I IFN signaling results in macrophage polarization toward a pro-inflammatory profile in infected lung tissues.

\section{The effect of type I IFNs on T cell recruitment and activation during early $M$. bovis infection}

In order to evaluate the effect of Type I IFNs during $M$. bovis infection on priming or trafficking of $\mathrm{T}$ lymphocytes, we examined populations of $\mathrm{CD}^{+}$and $\mathrm{CD}^{+} \mathrm{T}$ cells in the lung and spleen tissues of infected $\alpha$ IFNAR1 or Isotype treated mice. Flow cytometry results revealed that at both 21 and 84 days post-infection, no significant difference was observed in $\mathrm{CD}^{+}$and $\mathrm{CD}^{+} \mathrm{T}$ cell populations in the lung and spleen tissues of $\alpha$ IFNAR 1 and Isotype treated mice (Additional file 3: Figure S3A, S3B).

\section{Discussion}

The distribution of tuberculosis is worldwide and it remains one of the deadliest infectious diseases of human and animals. Increasing evidence suggests that cytokines are key mediators in host protective response against $M$. tuberculosis infection [27]. It has been reported that IFN- $\gamma$ [27], TNF- $\alpha$ [28], and IL-12 [29] are critical cytokines in controlling $M$. tuberculosis infection in mouse model of tuberculosis. On the other hand, emerging studies suggests that Type I IFN plays a critical role in chronic tuberculosis. Though several studies have reported that Type I IFN contribute in the activation of host immune cells during in vitro infection of $M$. tuberculosis, a number of other studies have also reported the adverse impact of these cytokines on the recovery of infection in vivo [14-16]. In the current study, we addressed this issue by investigating the effects of the IFNAR1 antibody in the regulation of Type I IFN in $M$. bovis infection both in vivo and in vitro. These observations suggest that the inhibition of IFNAR1 significantly extenuates pulmonary immunopathology, reduced the recruitment of neutrophils to the lung, modulate the polarization of macrophages, and promote antimycobacterial Th1 response during $M$. bovis infection. Our observations are in line with early studies showing a key role of host innate immune cells in investigating the outcome of mycobacterial infection in vivo [30, 31].

In the previous studies, IFN-depended gene signatures were observed in the blood of acute phase of tuberculosis, as well as, in the patient of chronic stage of infection from UK, Indonesia and South Africa [10, 11, 32]. In addition, it is reported that blood transcriptional profiles of individuals in the early stage of tuberculosis were dominated by Type I IFN-inducible gene profiles, that were associated with radiographic detectable lung lesions and subsided with proper therapy [10]. In addition, high numbers of IFN-mediated signatures were also found in mice infected with $M$. tuberculosis, as well as, in $M$. bovis-infected cattle [13, 32-34]. Similarly, our results showed that Type I IFN and Type I IFN-mediated genes were significantly increased in the lung and spleen tissues of mice challenged with $M$. bovis as compared to 
A

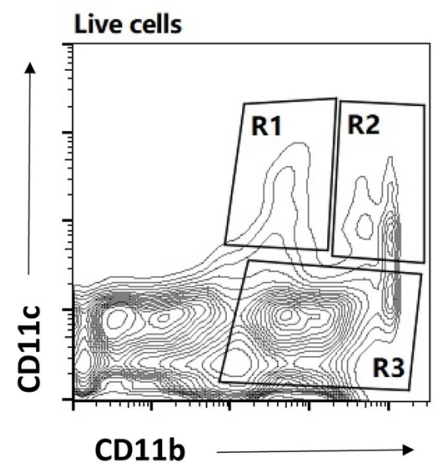

C

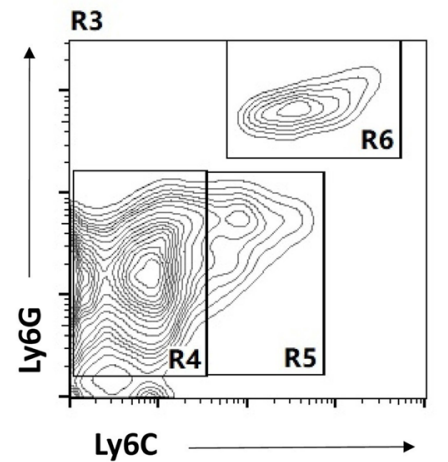

E

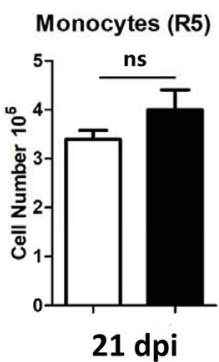

G

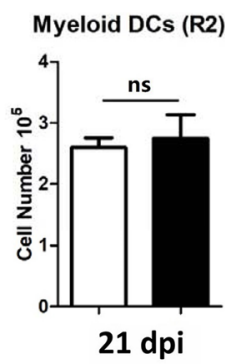

Recruited macrophages (R4)

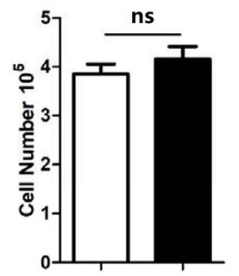

$21 \mathrm{dpi}$
B

Alveolar macrophages (R1)

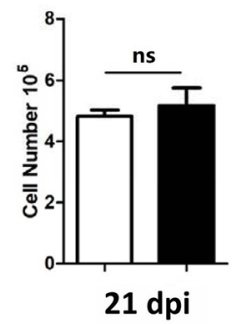

$\mathbf{F}$

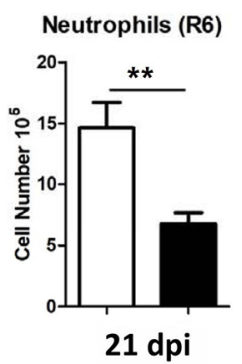

H

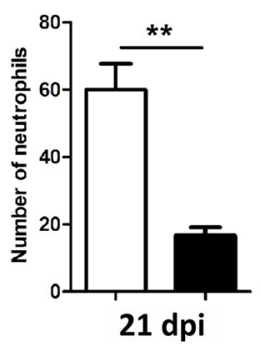

L

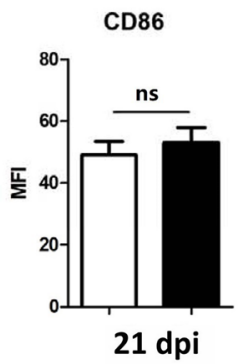

$\square$ Isotype $\alpha$ IFNAR1

$\square$ Isotype a IFNAR1
I

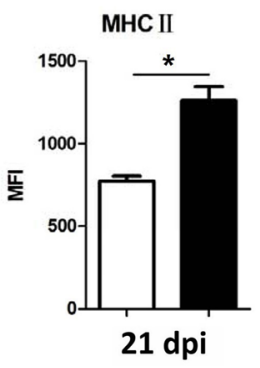

J

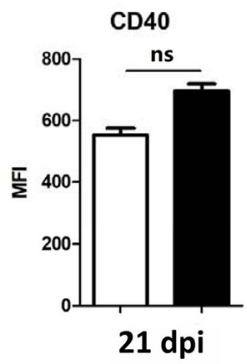

K

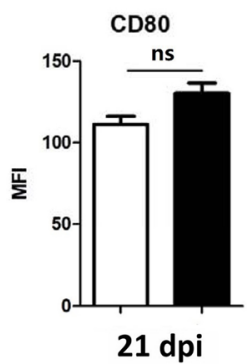

Fig. 4 (See legend on next page.) 


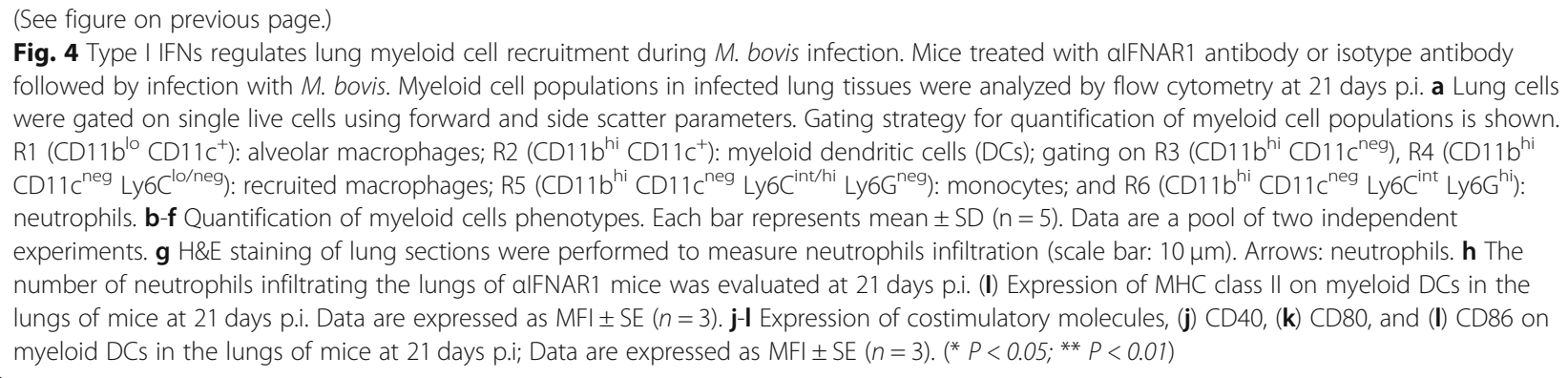

uninfected control mice. Overexpression of Type I IFN in the mouse infected with $M$. tuberculosis has shown the adverse effects of Type I IFN signaling during tuberculosis. It has been studied that direct instillation of purified murine IFN- $\alpha / \beta$ into the lungs during $M$. tuberculosis infection is highly deleterious to the host [14]. Similarly, increased induction of IFN $\alpha / \beta$ production during $M$. tuberculosis infection after treatment with TLR3 agonist results into enhanced bacterial burdens and exacerbated pulmonary immunopathology [18, 20]. Likewise, blockade of counter regulators of Type I IFN signaling, MAPK kinase kinase 8 (MAP $3 \mathrm{~K} 8$; also known as TPL2), that activates signaling downstream of TLRs, results into over-production of Type I IFN that attenuated the host-immune defense mechanism to reduce the growth and survival of $M$. tuberculosis or L. monocytogenes [35, 36]. Conversely, these studies indicated the absence of Type I IFN signaling is associated with a decreased bacterial burden. Similarly, we found that during $M$. bovis infection, lung lesions were overall extenuated by the blockade of Type I IFN signaling and the pathological severity and host survival was correlated with bacterial load.

The signaling cascades mediating the regulation of Type I IFN, associated with the severity of disease, are not fully elucidated. Reports demonstrated that Type I IFN contributes to host-susceptibility to M. tuberculosis infection by different mechanisms such as production of IL-10 and counter regulation of IL-1 $\beta /$ PGE2, and IL-12/IFN- $\gamma$ axis mediates protective immune responses. Furthermore, Type I IFN inhibits host immune defense mechanism by negative regulation of IL- $1 \alpha$ and IL- $1 \beta$ in tuberculosis [37-39]. Recently, it has been reported that IL-1 $\beta$ negatively regulates the production of Type I IFN through prostaglandin E2 (PGE2)-mediated mechanism. By promoting the levels of PGE2 during $M$. tuberculosis infection, IL- $1 \beta$ leads to inhibition of Type I IFN production thus contributes to reduce the susceptibility of mice to $M$. tuberculosis infection [20]. In our study, we found that blockade of Type I IFN signaling reduced the production of IL-10 while enhanced the production of IL- $1 \beta$ in lung homogenates during early stage of $M$. bovis infection. Previous studies have reported that IL-12 and TNF- $\alpha$ production was negatively regulated in human monocytes treated with IFN- $\alpha$ or IFN- $\beta$ [40] and similar findings were observed in murine macrophages [39]. In addition, it is reported that Type I IFN induce the production of the antiinflammatory cytokine, IL-10 in macrophages [37, 39]. Furthermore, the negative regulation of IL-12 and TNF- $\alpha$ by Type I IFN signaling was blocked in the absence of IL10 in M. tuberculosis-infected macrophages [39]. It is also known that $M$. tuberculosis actively suppresses the production of IL-12 and TNF- $\alpha$ in macrophages, independent of Type I IFN signaling, by the secretion of ESAT-6/CFP10 [33]. It is broadly accepted that IL-12 and TNF- $\alpha$ both are essential for host resistance against infection but overproduction of these cytokines may contribute towards immunopathology. Our results showed that blocking of IFNR1 did not affect IL-12 and TNF- $\alpha$ production during M. bovis infection. In addition, Type I IFNs can also down regulate IFN- $\gamma$ signaling by inhibiting IFNGR1 suggesting a detrimental role of Type I IFNs in the pathogenesis of M. tuberculosis via antagonizing host-protective functions of IFN- $\gamma$ [39-41]. In our current study, we observed that blockade of Type I IFN signaling promotes the production of IFN- $\gamma$ in lung homogenates during early stage of $M$. bovis infection. Collectively, these results reveal that Type I IFN may contribute to host-pathogen interaction locally by regulating the induction of host-protective cytokines at the site of infection.

It has been unveiled that Type I IFN increase the susceptibility of alveolar macrophages [19] and recruit immunologically exhausted myeloid cells to the site of infection, which contribute to the spread of infection and pulmonary inflammation $[18,19]$. In addition, enhanced IFN-mediated genes in the blood neutrophils and monocytes were detected, but not in $\mathrm{CD}^{+}$or $\mathrm{CD} 8^{+} \mathrm{T}$ cells, in patients with active phase of tuberculosis $[10,42]$ suggesting the role of monocytes and neutrophils in the Type I IFN-mediated pathogenesis of tuberculosis. Panteleev and colleagues reported that neutrophils have a positive correlation with the extent of lung injury, bacterial dissemination, and "Timika X-ray score" [43]. These features illustrate that neutrophils are not efficient to inhibit mycobacterial replication in comparison to residing macrophages of lung. It also implicates that the existence of 


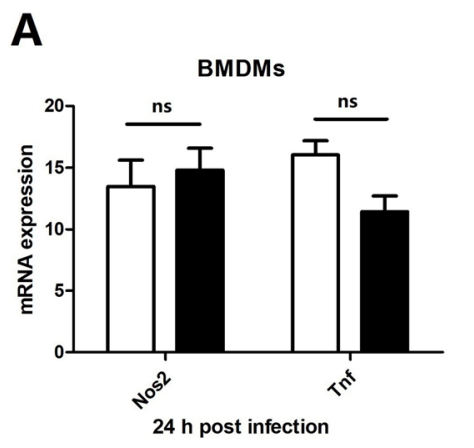

C

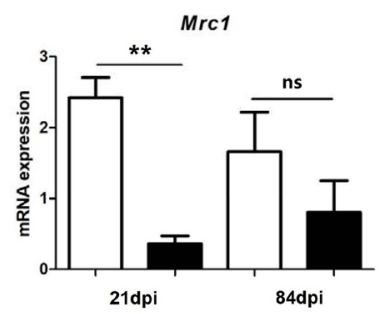

$\mathbf{F}$

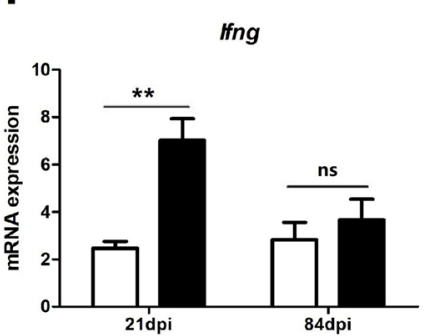

I

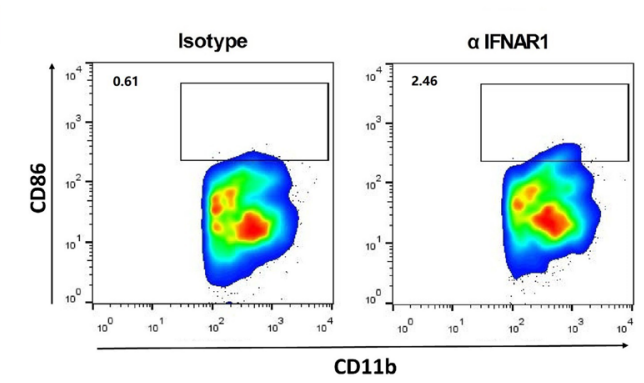

K

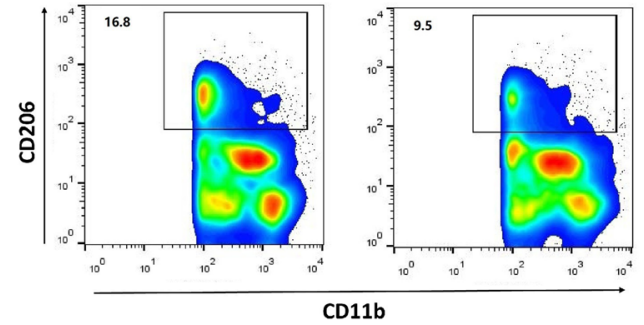

BMDMs

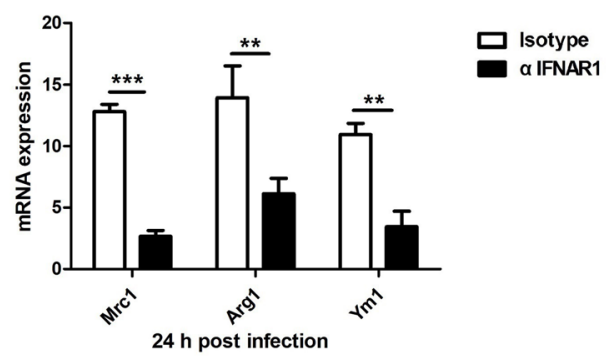

E

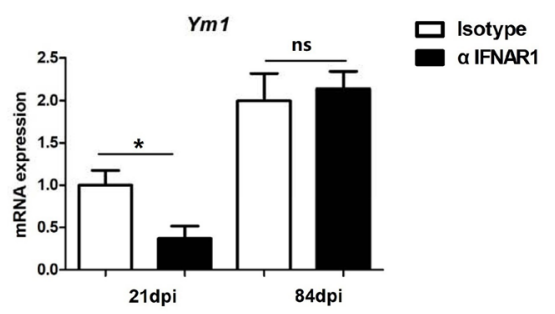

H
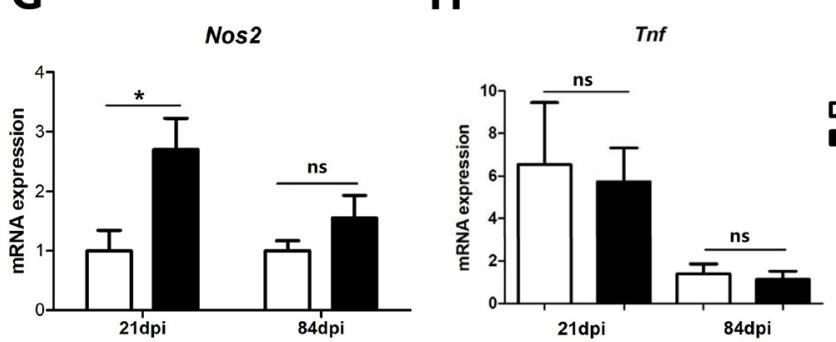

$\square$ Isotype

a IFNAR1

J

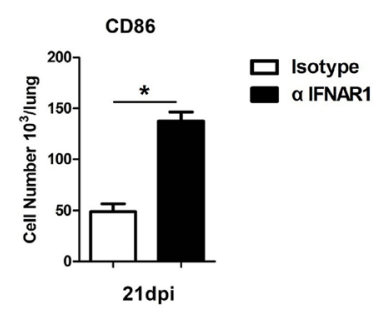

$\mathbf{L}$

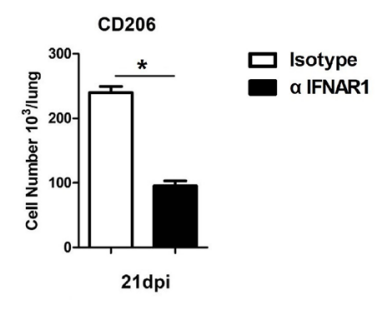

Fig. 5 (See legend on next page.) 
(See figure on previous page.)

Fig. 5 Type I IFNs drive macrophage polarization toward an anti-inflammatory profile in M. bovis-infected lungs. a-b BMDMs were infected with M. bovis at a multiplicity of infection (MOI) of 10 in the presence or absence of the alFNAR1 antibody. Relative expression of macrophage M2 (Arg1, Ym1, and Mrc1) and M1 (Nos2 and Tnf) polarization gene markers were quantified by qRT-PCR at $24 \mathrm{hpi}$. Data were normalized to housekeeping gene $\beta$-actin. Mice were infected with M. bovis as mentioned above (Fig. 4). c-e) qRT-PCR was performed for quantification of M2 (Arg1, Ym1, and Mrc1) and (f-h) M1 (Ifng, Nos2 and Tnf) polarization markers in the lungs of infected mice. The effect of alFNAR1 antibody treatment on polarization of macrophages in the lung tissues of mice infected with M. bovis at 21 days p.i. Representative flow cytometric plots of CD86-expressing (M1) (i-j) and CD206-expressing (M2) macrophages and relative cell numbers (k-l). Each bar represents mean \pm SD $(n=5)$. Data are a pool of two independent experiments

neutrophils in TB associated inflammation promotes the induction of lung pathology rather than protection thus neutrophils may serve as a "Trojan horse" for the dissemination of mycobacteria [44]. In consistent with these results, we found significantly lower number of neutrophils at 21 days after $M$. bovis infection in aIFNAR1 treated mice. These findings suggest that Type I IFN participates in the development of acute inflammation in the lung tissue mediated by neutrophils during $M$. bovis infection in mice.

The polarization of macrophages into M1 class is specifically a pro-inflammatory phenotype with antibacterial ability while M2 class of macrophages are specialized in tissue repairing and also resist to helminths infection [45]. It has been reported that B cell-restricted Myd88 deficient mice show an increased M2 macrophages in the lungs tissue during M. tuberculosis infection which is associated with increased bacterial load [46]. Furthermore, C-type lectin receptor (DCIR) deficiency results in inhibition of Type I IFN signaling which in turn leads to macrophage activation and polarization into antimicrobial M1 phenotype [47]. In line with these results, we noticed that blockade of Type I IFN signaling modulates macrophage polarization towards a proinflammatory profile. Collectively, these results reveal that innate signaling in the lung mediated by Type I IFN production, leads to polarization of macrophage into M2like profile in the early stage of $M$. bovis infection.

Previously, IFN- $\beta$ has been used for the control of multiple sclerosis, possibly via inhibitory effect on the function of T helper 1 (Th1) cells, but the detailed mode of action is not fully elucidated yet $[48,49]$. In the case of TB, inhibition of Type I IFN signaling in DCs mediated by STAT1 results into high expression of IL-12 and also stimulate the differentiation of $\mathrm{T}$ cells into Th1 cell population [47]. However, Type I IFN signaling also mediates the survival of activated CD4 $\mathrm{T}$ cells and its role in the activation of effector CD8 T cells has been investigated in vaccination programs [50]. In addition, recombinant Type I IFN shows direct adjuvant activity in vivo contributing to the both humoral and $\mathrm{T}$ cell mediated immune responses [51,52]. However, the severity of $M$. tuberculosis infection by Poly-ICLC is not owing to the attenuation of effector Th1 cell function [18]. Evidence suggests that mice deficient in IFNAR1 are more resistant to the infection of $M$. tuberculosis than WT mice, while no significant effect on $\mathrm{T}$ cells function was observed [19]. Quantitative analysis of antigen-specific Th1 cells parameters revealed that Th1 cells response play a minor role in determining the severity of tuberculosis [43]. As depicted by our current data, M. bovis exploits Type I IFN signaling pathway to evade the host immune response but it does not alter the $\mathrm{T}$ cells recruitment and activation in the lung and spleen tissues.

\section{Conclusion}

In conclusion, we found that blockade of Type I IFN signaling reduces the recruitment of neutrophils to the lung, modulates the polarization of macrophages toward a pro-inflammatory profile, inhibits the production of IL-10, promotes the production of IFN- $\gamma$ and IL-1 $\beta$, and has no effects on $\mathrm{T}$ cells function in the early acute phase of the disease. Moreover, Type I IFN signature gene phenotype provides a potential diagnostic tool and may have implications for vaccine development, and can be exploited as a target in the host-directed therapy to combat mycobacterial infection.

\section{Supplementary information}

Supplementary information accompanies this paper at https://doi.org/10. 1186/s12879-019-4654-3.

\section{Additional file 1: Figure S1. M.bovis induces type I interferon} production in C57BL/6 mice. (A-C) Wild type female C57BL/6 mice were challenged by i.n route with 100 CFU of $M$. bovis or PBS. (A) IFN- $\beta$ and (B) IFNAR1 expression in the spleen tissue were detected by qRT-PCR. ( $C$ and D) Representative images of spleen sections for (C) IFN- $\beta$ and (D) IFNAR1 expression by $\mathrm{IHC}$ method; scale bars, $20 \mu \mathrm{m}$. (E and F) IFN-responsive genes such as Irf7, Oas2 and Isg15 were checked by qRT-PCR at (E) 21 and (F) 84 days p.i. Gene expression values were normalized to the housekeeping gene $\beta$-actin. Data is presented as mean \pm SD $(n=3)$ (* $P<0.05$; ** $P<0.01$; *** $P<0.001$ ).

Additional file 2: Figure S2. IFNAR1 blockade inhibits Type I IFN signaling in vivo. C57BL/6 mice were treated with alFNAR1 or isotype antibodies one day prior to M. bovis infection. (A and B) The relative mRNA expression of Oas2, Isg15 and Irf7 were calculated by qRT-PCR in (A) lung and (B) spleen $(n=5)$. (C) The concentration of serum IFN- $\beta$ was calculated by ELISA at 21 days p.i $(n=5)$. Data is presented as mean \pm SD from two independent experiments.

Additional file 3: Figure S3. IFNAR1 blockade do not affect the population of $\mathrm{CD}^{+}$or $\mathrm{CD}^{+} \mathrm{T}$ cells in vivo. C57BL/ 6 mice were treated with alFNAR1 or isotype antibodies one day prior to $M$. bovis infection. At 
21 and 84 days p.i, cell suspensions from lung and spleen were stimulated in vitro with ESAT-6:1-20 $(10 \mu \mathrm{g} / \mathrm{ml})$. (A-B) Representative flow cytometric plots of $\mathrm{CD}^{+}$or $\mathrm{CD} 8^{+} \mathrm{T}$ cells by ICS applied on total (right panel) lung cells and (left panel) splenocytes of mice at 21 and 84 days p.i $(n=3)$. Data is presented from two independent experiments.

\section{Abbreviations}

BSL3: Biosafety conditions level 3; CFU: Colony forming units; ELISA: Immunosorbent assay; H\&E: Hematoxylin and eosin; IHC: Immunohistochemistry; IL-10: Interleukin-10; M. bovis: Mycobacterium bovis; M. tuberculosis: Mycobacterium tuberculosis; PCR: Polymerase chain reaction; TB: Tuberculosis; Type I IFN: Type I interferon

\section{Acknowledgments}

We thank China Agricultural University for providing the Biosafety Level-3 Laboratories for cell and animal experiments using M. bovis infection.

\section{Authors' contributions}

JW performed the major experiments. Y S, J N, HD and N S helped in experiments related to cell culture and Quantitative real time-PCR. TH, K Z, Y $L, J Y, M H M, G C$, and $M L$ helped in all animal experiments and flow cytometry assay. TH, D Z and X Z gave valuable suggestion throughout the experiments and critically reviewed the article for English correction before final submission. All authors have read and approved the final version of manuscript before submission.

\section{Funding}

This work was supported by the National Key Research and Development Program (Project No. 2017YFD0500901), China Agriculture Research System (No. CARS-36), National Natural Science Foundation of China (Project No. 31572487, No.31873005); and the MoSTRCUK international cooperation project (Project No. 2013DFG32500); and the High-end Foreign Experts Recruitment Program (Project No. GDW20151100036, GDW20161100071).

\section{Availability of data and materials}

All data generated or analyzed during this study are included in the manuscript and the supporting information are available in the supplementary materials.

\section{Ethics approval}

Animal experiments were carried out under the rules of laboratory animals care, Ministry of Science and Technology People's Republic of China and approved animal care and use committee (IACUC) procedures with license number of 20,110,611-01 at China Agricultural University, Beijing. The proposal for animal experiment was assessed and approved by The Laboratory Animal Ethical Committee of China Agricultural University, Beijing, China.

\section{Consent for publication}

N/A

\section{Competing interests}

The authors declare that they have no competing interests.

\section{Author details}

${ }^{1}$ Key Laboratory of Animal Epidemiology and Zoonosis, Ministry of Agriculture, National Animal Transmissible Spongiform Encephalopathy Laboratory, College of Veterinary Medicine, China Agricultural University, Beijing, China. Institute of Laboratory Animal Sciences, Chinese Academy of Medical Sciences (CAMS), Comparative Medicine Center, Peking Union Medical College (PUMC), Beijing, China. ${ }^{3}$ School of Agriculture, Ningxia University, Ningxia, China.

\section{Received: 31 July 2019 Accepted: 22 November 2019}

Published online: 04 December 2019

\section{References}

1. World Health Organization.(2018). Global tuberculosis report 2018. World Health Organization, Geneva. 277 pp.
2. Renwick AR, White PC, Bengis RG. Bovine tuberculosis in southern African wildlife: a multi-species host-pathogen system. Epidemiol Infect. 2007;135(4): 529-40.

3. Flynn JL, Chan J. Immunology of tuberculosis. Annu Rev Immunol. 2001; 19(1):93-129.

4. North RJ, Jung Y-J. Immunity to tuberculosis. Annu Rev Immunol. 2004; 22(1):599-623.

5. Cooper AM. Cell-mediated immune responses in tuberculosis. Annu Rev Immunol. 2009;27(1):393-422.

6. O'Garra A, et al. The immune response in tuberculosis. Annu Rev Immunol. 2013;31(1):475-527.

7. Pestka S, Krause CD, Walter MR. Interferons, interferon-like cytokines, and their receptors. Immunol Rev. 2004;202(1):8-32.

8. Ivashkiv LB, Donlin LT. Regulation of type I interferon responses. Nat Rev Immunol. 2014;14(1):36-49.

9. Piehler J, et al. Structural and dynamic determinants of type I interferon receptor assembly and their functional interpretation. Immunol Rev. 2012; 250(1):317-34.

10. Berry MP, et al. An interferon-inducible neutrophil-driven blood transcriptional signature in human tuberculosis. Nature. 2010;466(7309): 973-7.

11. Esmail $\mathrm{H}$, et al. Complement pathway gene activation and rising circulating immune complexes characterize early disease in HIV-associated tuberculosis. Proc Natl Acad Sci. 2018;115(5):E964.

12. Singhania, A., et al, A modular transcriptional signature identifies phenotypic heterogeneity of human tuberculosis infection. bioRxiv, 2017: p. 216879.

13. Wang J, et al. Expression pattern of interferon-inducible transcriptional genes in neutrophils during bovine tuberculosis infection. DNA Cell Biol. 2013:32(8):480-6.

14. Manca, C., et al, Virulence of a \&lt;em\&gt;Mycobacterium tuberculosis\&lt;/ em\&gt; clinical isolate in mice is determined by failure to induce Th1 type immunity and is associated with induction of IFN- $\alpha / \beta$. Proc Natl Acad Sci, 2001. 98(10): p. 5752.

15. Manca C, et al. Hypervirulent M. tuberculosis W/Beijing strains Upregulate type I IFNs and increase expression of negative regulators of the Jak-stat pathway. J Interf Cytokine Res. 2005;25(11):694-701.

16. Ordway, D., et al, The Hypervirulent \&lt;em\&gt;Mycobacterium tuberculosis\&lt;/em\&gt; Strain HN878 Induces a Potent TH1 Response followed by Rapid Down-Regulation. J Immunol, 2007. 179(1): p. 522.

17. Carmona J, et al. Mycobacterium tuberculosis strains are differentially recognized by TLRs with an impact on the immune response. PLoS One. 2013;8(6):e67277.

18. Antonelli LR, et al. Intranasal poly-IC treatment exacerbates tuberculosis in mice through the pulmonary recruitment of a pathogen-permissive monocyte/macrophage population. J Clin Invest. 2010;120(5):1674-82.

19. Dorhoi A, et al. Type I IFN signaling triggers immunopathology in tuberculosis-susceptible mice by modulating lung phagocyte dynamics. Eur J Immunol. 2014;44(8):2380-93.

20. Mayer-Barber KD, et al. Host-directed therapy of tuberculosis based on interleukin-1 and type I interferon crosstalk. Nature. 2014;511(7507):99-103.

21. Hussain $T$, et al. MicroRNA 27a-3p regulates antimicrobial responses of murine macrophages infected by Mycobacterium avium subspecies paratuberculosis by targeting Interleukin-10 and TGF-beta-activated protein kinase 1 binding protein 2. J Front Immunol. 2017;8:1915.

22. Wang J, et al. MicroRNA-199a inhibits cellular autophagy and Downregulates IFN- $\beta$ expression by targeting TBK1 in Mycobacterium bovis infected cells. Front Cell Infect Microbiol. 2018 Jul 10;8:238.

23. Logan KE, et al. Development of a Mycobacterium bovis intranasal challenge model in mice. Tuberculosis (Edinb). 2008 Sep;88(5):437-43.

24. Cafaro A, et al. HIV-1 tat protein vaccination in mice infected with Mycobacterium tuberculosis is safe, immunogenic and reduces bacterial lung pathology. BMC Infect Dis. 2016 Aug 22;16(1):442.

25. Kurawattimath $V$, et al. A modified serial blood sampling technique and utility of dried-blood spot technique in estimation of blood concentration: application in mouse pharmacokinetics. Eur J Drug Metab Pharmacokinet. 2012 Mar;37(1):23-30.

26. Hussain T., et al, Nilotinib: A Tyrosine Kinase Inhibitor Mediates Resistance to Intracellular Mycobacterium Via Regulating Autophagy. Cells. 2019 ;8(5). pii: E506.

27. Cooper AM, et al. Disseminated tuberculosis in interferon gamma genedisrupted mice. J Exp Med. 1993;178(6):2243. 
28. Flynn $J$, et al. Tumor necrosis factor-a is required in the protective immune response against mycobacterium tuberculosis in mice. Immunity. 1995;2(6): 561-72.

29. Cooper AM, et al. The role of interleukin-12 in acquired immunity to Mycobacterium tuberculosis infection. Immunology. 1995;84(3):423-32.

30. Davis JM, Ramakrishnan L. The role of the granuloma in expansion and dissemination of early tuberculous infection. Cell. 2009;136(1):37-49.

31. Bold TD, Ernst JD. Who benefits from granulomas, mycobacteria or host? Cell. 2009;136(1):17-9.

32. Ottenhoff THM, et al. Genome-wide expression profiling identifies type 1 interferon response pathways in active tuberculosis. PLoS One. 2012;7(9): e45839

33. Stanley SA, et al. The type I IFN response to infection with Mycobacterium tuberculosis requires ESX-1-mediated secretion and contributes to pathogenesis. J Immunol. 2007;178(5):3143-52.

34. Wu K, et al. An interferon-related signature in the transcriptional Core response of human macrophages to Mycobacterium tuberculosis infection. PLoS One. 2012;7(6):e38367.

35. McNab FW, et al. TPL-2-ERK1/2 signaling promotes host resistance against intracellular bacterial infection by negative regulation of type I IFN production. J Immunol. 2013;191(4):1732-43.

36. Dauphinee SM, et al. Contribution of increased ISG15, ISGylation and deregulated type I IFN signaling in Usp18 mutant mice during the course of bacterial infections. Genes Immun. 2014;15(5):282-92.

37. Mayer-Barber KD, et al. Innate and Adaptive Interferons Suppress IL-1a and IL-1 $\beta$ Production by Distinct Pulmonary Myeloid Subsets during Mycobacterium tuberculosis Infection. Immunity. 2011;35(6):1023-34.

38. Mayer-Barber KD, et al. Caspase-1 independent IL-1 beta production is critical for host resistance to mycobacterium tuberculosis and does not require TLR signaling in vivo. J Immunol. 2010;184(7):3326-30.

39. McNab FW, et al. Type I IFN induces IL-10 production in an IL-27independent manner and blocks responsiveness to IFN-gamma for production of IL-12 and bacterial killing in Mycobacterium tuberculosisinfected macrophages. J Immunol. 2014;193(7):3600-12.

40. de Paus RA, et al. Inhibition of the type I immune responses of human monocytes by IFN-alpha and IFN-beta. Cytokine. 2013;61(2):645-55.

41. Teles RMB, et al. Type I interferon suppresses type II interferon-triggered human anti-mycobacterial responses. Science. 2013;339(6126):1448.

42. Bloom Cl, et al. Transcriptional blood signatures distinguish pulmonary tuberculosis, pulmonary Sarcoidosis, Pneumonias and Lung Cancers. PLOS ONE. 2013;8(8):e70630.

43. Panteleev AV, et al. Severe tuberculosis in humans correlates best with neutrophil abundance and lymphocyte deficiency and does not correlate with antigen-specific CD4 T-cell response. Front Immunol. 2017:8:963.

44. Eruslanov EB, et al. Neutrophil responses to Mycobacterium tuberculosis infection in genetically susceptible and resistant mice. Infect Immun. 2005 73(3):1744-53.

45. Murray PJ, Wynn TA. Protective and pathogenic functions of macrophage subsets. Nat Rev Immunol. 2011;11(11):723-37.

46. Bénard A, et al. B cells producing type I IFN modulate macrophage polarization in tuberculosis. Am J Respir Crit Care Med. 2018;197(6):801-13.

47. Troegeler A, et al. C-type lectin receptor DCIR modulates immunity to tuberculosis by sustaining type I interferon signaling in dendritic cells. Proc Natl Acad Sci. 2017;114(4):E540.

48. Boivin $N$, et al. Interferon- $\beta$ suppresses murine Th1 cell function in the absence of antigen-presenting cells. PLoS One. 2015;10(4):e0124802.

49. Kavrochorianou N, Markogiannaki M, Haralambous S. IFN-beta differentially regulates the function of T cell subsets in MS and EAE. Cytokine Growth Factor Rev. 2016;30:47-54.

50. Gautier $\mathrm{G}$, et al. A type I interferon autocrine-paracrine loop is involved in toll-like receptor-induced interleukin-12p70 secretion by dendritic cells. Exp Med. 2005;201(9):1435-46.

51. Proietti $\mathrm{E}$, et al. Type I IFN as a natural adjuvant for a protective immune response: lessons from the influenza vaccine model. J Immunol. 2002;169(1):375-83.

52. Le Bon A, et al. Type I Interferons potently enhance Humoral immunity and can promote Isotype switching by stimulating dendritic cells in vivo. Immunity. 2001;14(4):461-70.

\section{Publisher's Note}

Springer Nature remains neutral with regard to jurisdictional claims in published maps and institutional affiliations.

\section{Ready to submit your research? Choose BMC and benefit from:}

- fast, convenient online submission

- thorough peer review by experienced researchers in your field

- rapid publication on acceptance

- support for research data, including large and complex data types

- gold Open Access which fosters wider collaboration and increased citations

- maximum visibility for your research: over $100 \mathrm{M}$ website views per year

At BMC, research is always in progress.

Learn more biomedcentral.com/submissions 